\title{
Value of information for climate observing systems
}

\author{
Roger Cooke • Bruce A. Wielicki • David F. Young • \\ Martin G. Mlynczak
}

Published online: 23 July 2013

(c) The Author(s) 2013. This article is published with open access at Springerlink.com

\begin{abstract}
The Interagency Working Group Memo on the social cost of carbon is used to compute the value of information (VOI) of climate observing systems. A generic decision context is posited in which society switches from a business as usual (BAU) emissions path to a reduced emissions path upon achieving sufficient confidence that a trigger variable exceeds a stipulated critical value. Using assessments of natural variability and uncertainty of measuring instruments, it is possible to compute the time at which the required confidence would be reached under the current and under a new observing system, if indeed the critical value is reached. Economic damages (worldwide) from carbon emissions are computed with an integrated assessment model. The more accurate observing system acquires the required confidence earlier and switches sooner to the reduced emissions path, thereby avoiding more damages which would otherwise be incurred by BAU emissions. The difference in expected net present value of averted damages under the two observing systems is the VOI of the new observing system relative to the existing system. As illustration, the VOI for the proposed spaceborne CLARREO system relative to current space-borne systems is computed. Depending on details of the decision context, the VOI ranges from 2 to 30 trillion US dollars.
\end{abstract}

Electronic supplementary material The online version of this article (doi:10.1007/s10669-013-9451-8) contains supplementary material, which is available to authorized users.

R. Cooke $(\square)$

Resources for the Future, Washington, DC, USA

e-mail: Cooke@rff.org

B. A. Wielicki · D. F. Young · M. G. Mlynczak

NASA Langley Research Center, Hampton, VA, USA
Keywords Value of information - Climate observing system · Social cost of carbon · DICE - CLARREO

\section{Introduction}

In early 2010, the United States government published estimates of the social cost of carbon for use in regulatory cost-benefit analysis (Interagency Working Group on Social Cost of Carbon; IWG SCC 2010, hereafter SCC). The estimates concern the monetized climatic benefits of regulations for the transportation, electricity, and other economic sectors that reduce carbon emissions. Since formal publication of the SCC, it has been employed in more than 20 regulations ranging from fuel economy standards for vehicles to air pollution regulations for power plants to energy efficiency standards for appliances and equipment (Kopp and Mignone 2012).

The value of learning about climate change has been emphasized in a host of papers including Kelly and Kolstad (1999), O'Neill et al. (2006), Webster et al. (2008), and McInerney et al. (2011). The related notion of value of design has been used in appraising aeronautical systems (Brathwaite and Saleh 2013). This paper uses the SCC to compute the value of information (VOI) provided by projected climate observing system (COS) improvements designed to learn about key climate parameters faster than existing observations. For background on VOI, see Laxminarayan and Macauley (2012). The key to computing this VOI is to place this new COS in a decision context where its information can be used. Indeed, if the new information is not used, then the COS can be valued only in terms of pure knowledge accretion, and its potential social value is lost. The VOI formalism is the essential tool in structuring the decision problem in which the social value 
of a new COS can be computed. Although based on the US baseline for computing the SCC, the climate damages are worldwide. Switching from a business as usual (BAU) to a reduced emissions path (see Sect. 4) upon achieving a given level of confidence that a climate parameter has been exceeded avoids damages worldwide whose net present value (NPV) runs into tens of trillions of US dollars.

To illustrate VOI calculations of COSs, this paper considers the proposed CLARREO space-borne observing system. Driving this choice is the fact that key accuracy parameters of this system as compared to the current spacebased systems have been computed (Wielicki et al. 2013). This initial VOI estimate uses several simplifying assumptions. Besides the assumptions underlying the SCC, we use the integrated assessment model DICE coupling climate change to economic damages (Nordhaus 2008), and we simplify the decision context in many ways. Sensitivity tests of selected parameters suggest that, while total societal costs vary greatly, the VOI of accelerated climate change information is relatively robust against the selection of a reduced emissions scenario, a climate trigger for switching to the reduced emissions scenario, and the level of confidence required for the switch. The main message of this paper, however, is that VOI calculations of new COSs are possible, and should be used to assess their potential contribution, beyond a current baseline, of new observing systems.

Section 1 describes the SCC. Section 2 discusses the COS improvements treated in this paper. Section 3 describes the decision context for evaluating the VOI for the improved COS. Section 4 presents results, and a final section summarizes and concludes. Supplementary Online Material gives the mathematical basis for learning a trend from noisy signals, based on Leroy et al. (2008). The SSC explicitly introduced quantitative uncertainty analysis into the social cost of carbon. This is certainly not the last word on the subject; see Cooke (2012) for background on uncertainty analysis and climate change.

\section{Interagency memo on the social cost of carbon}

The SCC is intended to be a comprehensive estimate of the economic impacts of climate change, including impacts ranging from (but not limited to) changes in crop productivity, loss of land to sea level rise, health effects, and potential economic catastrophes associated with Earth system tipping points. The SCC does not currently include costs due to changing international political stability, ocean acidification, species and wildlife loss, or ecosystem services.

Calculating the SCC involves specifying a baseline emissions scenario, computing the NPV of the resulting climate damage, and subtracting this from the NPV of damages resulting from adding one extra unit of carbon emissions in the current time period. Three discount rates are stipulated for the calculation $2.5,3$, and $5 \%$. The range of discount rates is chosen to acknowledge uncertainties in the appropriate rates for long-term global climate change (Arrow et al. 1996; Stern 2008). Three integrated assessment models (IAMs) are used to couple emissions to temperature rise, and to climate damages: DICE (Nordhaus 2008), FUND (Anthoff and Tol 2010; Tol 2002) and PAGE (Hope 2006). These IAMs combine simple climate, carbon cycle, and economic models with assumptions about population and income growth, technological change, and public policies.

For SCC calculations, equilibrium climate sensitivity (CS) is one of the primary uncertainties. The CS probability distribution is stipulated to be that of Roe and Baker (2007), with modifications to improve consistency with the IPCC AR4 conclusions. CS is defined as the equilibrium global temperature increase for doubled $\mathrm{CO}_{2}$; its cumulative frequency distribution and probability density function used in SCC are shown in Fig. 1. The probability density of $\mathrm{CS}$ has a median value of $3{ }^{\circ} \mathrm{C}$, drops rapidly for values below $2{ }^{\circ} \mathrm{C}$, but drops slowly for high CS values until it is truncated at a value of $10{ }^{\circ} \mathrm{C}$. The range for $66 \%$ probability is between 2 and $4.5^{\circ} \mathrm{C}$. The 5 th percentile is $1.7^{\circ} \mathrm{C}$, while the 95th percentile is $7.1{ }^{\circ} \mathrm{C}$ (IWG SCC 2010). The range of $\mathrm{CS}$ is critical for SCC calculations as the IAMs primarily link future climate change economic damages to a power of the global temperature change, with the typical relationship being quadratic. In this case, an uncertainty of CS of a factor of 4 (the $90 \%$ confidence range) can drive uncertainty in economic impacts of a factor of 16 .

There is a very wide range of uncertainty in estimates of the SCC due to the difficulty of assessing future policies, economic developments, the climate response to $\mathrm{CO}_{2}$ forcing, and other assumptions used in the analysis (Tol 2005; Kopp and Mignone 2012). The SCC acknowledges the many uncertainties involved and the need to update SCC estimates over time to reflect advances in the science and economics of climate impacts (IWG SCC 2010, p. 32$){ }^{1}$

In spite of these acknowledged uncertainties, the USSCC establishes a common decision context and a common baseline for rigorous VOI computations. This, for the first time, enables quantitative, monetary valuation of the social benefits of climate system observations.

\footnotetext{
${ }^{1}$ The interagency report (p. 32) states: "It is the hope of the interagency group that over time researchers and modelers will work to fill these gaps and that the SCC estimates used for regulatory analysis by the Federal government will continue to evolve with improvements in modeling.".
} 
Fig. 1 Cumulative frequency distribution of equilibrium CS used in the US-SCC calculations $(\lambda)$ (left), and corresponding probability distribution function of CS (right)

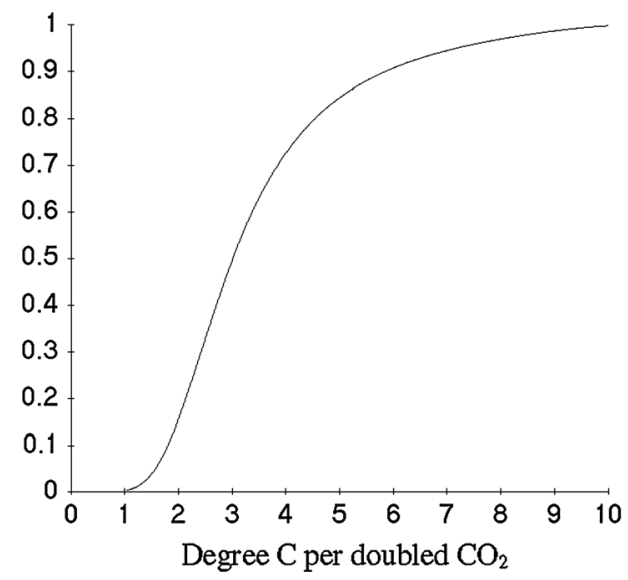

Table 1 shows SCC values at 5-year intervals during 2010-2050 in 2007 dollars, for the stipulated discount rates.

The SCC increases over time reflecting larger incremental damages as physical and economic systems become more stressed in response to greater climatic change. The SCC estimates for 2010 range from $\$ 5$ to $\$ 35$ per metric ton of $\mathrm{CO}_{2}$ equivalent depending on the discount rate. ${ }^{2}$ The SCC estimate also provides a 95th percentile value for low probability but high economic impacts as might be found for high CS and/or climate tipping points such as destabilization of major ice sheets.

\section{Climate observing system}

Earth is observed more completely today than at any other time in its history (GCOS 2011; GEO 2005, 2010). Yet major challenges remain, especially for observations of climate change, where unprecedented accuracy and rigor are required to observe subtle but critical climate changes on decade and longer timescales (Trenberth et al. 2012; GCOS 2011; NRC 2007). Major challenges remain in achieving traceability to international physical standards for space-based global observations (NRC 2007; Ohring et al. 2005; Ohring 2007), in providing independent observations and analysis to allow verification of surprising results (CCSP 2003), and in achieving sufficient sampling to document climate extremes (Trenberth et al. 2012).

Specific areas of uncertain climate change science with large impacts on societal costs include uncertainty in the rate and magnitude of sea level change from the major ice

\footnotetext{
${ }^{2} \mathrm{CO}_{2}$ equivalent is a metric measure to compare emissions from different greenhouse gases based on their global warming potential (GWP), the cumulative radiative forcing effects of a gas over a specified time horizon relative to a reference gas. For the procedure used by the US EPA in inventorying US greenhouse gases, the reference gas is carbon dioxide $\left(\mathrm{CO}_{2}\right)$. The $\mathrm{CO}_{2}$ equivalent for a gas is derived by multiplying the tons of the gas by its associated GWP.
}

Table 1 Social cost of $\mathrm{CO}_{2}, 2010-2050$ (2007 dollars per ton)

\begin{tabular}{lcllc}
\hline YearlDiscount rate & $5 \%$ avg & $3 \%$ avg & $2.5 \%$ avg & $3 \% 95$ th \\
\hline 2010 & 4.7 & 21.4 & 35.1 & 64.9 \\
2015 & 5.7 & 23.8 & 38.4 & 72.8 \\
2020 & 6.8 & 26.3 & 41.7 & 80.7 \\
2025 & 8.2 & 29.6 & 45.9 & 90.4 \\
2030 & 9.7 & 32.8 & 50.0 & 100.0 \\
2035 & 11.2 & 36.0 & 54.2 & 109.7 \\
2040 & 12.7 & 39.2 & 58.4 & 119.3 \\
2045 & 14.2 & 42.1 & 61.7 & 127.8 \\
2050 & 15.7 & 44.9 & 65.0 & 136.2 \\
\hline
\end{tabular}

Source: US Interagency Working Group (IWG SCC 2010, pp 1-2)

sheets in Greenland and Antarctica, uncertainty in CS including cloud and carbon cycle feedbacks, uncertainty in anthropogenic aerosol radiative forcing, and uncertainty in future ocean acidification (IPCC 2007). The list is not exhaustive, but serves to demonstrate the diversity of climate science challenges. Solving these challenges requires both improved observations as well as improved climate system predictive models. More accurate climate predictions, validated by improved observations, can then provide the basis for more cost-effective and lower risk climate policies.

Currently, there are no VOI estimates for climate observations or climate modeling science. In contrast, we do have more rigorously traceable estimates of the economic value of weather predictions (Morss et al. 2008; Katz and Murphy 2005; Teisberg et al. 2005; Freebairn and Zillman 2002). Such estimates can be based on an extensive past history of weather events and their economic impacts. Climate change, meanwhile, has its primary impacts well into the future, and is a very different prediction challenge than weather (Hurrell et al. 2009; IPCC 2007). Weather prediction is primarily a dynamical prediction based on initial conditions and predicting a specific place (your city) and a specific instant of time (to within 
hours) within a few days into the future. Climate prediction on decadal up to century scales is primarily an energetics prediction based on changing boundary conditions and predicting the climate system response over long time scales (decades to century) with spatial averages from local (city) to regional (continent) to global. As a result, weather prediction VOI metrics are not directly applicable to climate prediction. The problem of decade to century time scale climate science VOI is sufficiently daunting and complex that it has remained largely unexplored. Most climate-related VOI studies have focused on short-term seasonal prediction as opposed to long-term climate change (Katz and Murphy 2005).

Consideration of all of the above climate science uncertainties and their potential observational improvements is beyond the scope of the present paper. Instead, we focus on the crucial climate uncertainty identified in the US-SCC, the uncertainty in CS. This selection is made because of its large impact on potential future climate change societal impacts. As mentioned in Sect. 1, an uncertainty of a factor of 4 in CS leads to a factor of 16 uncertainty in future economic impacts (IWG SCC 2010). The selection of CS is also motivated by recent advances in more clearly defining the relationship between decadal change climate observation accuracy and uncertainty in CS (Wielicki et al. 2013; Soden et al. 2008). Finally, we focus on the space-borne component of climate observations because of its unique global perspective. This focus allows us to take an initial step toward more rigorous climate science VOI that can provide a basis for later expansion to a more complete range of climate science uncertainties.

Climate sensitivity is the result of a wide range of both negative (stabilizing) and positive (destabilizing) feedbacks. The Stefan-Boltzmann law provides the strongest negative feedback. As the Earth's surface warms, it emits greater infrared energy. Water vapor feedback is a strong positive feedback driven by the Clausius Clapeyron relationship (Soden and Held 2006; IPCC 2007). Ice albedo feedback is a moderately strong positive feedback (Soden et al. 2008). The major uncertainty in CS, however, is cloud feedback (IPCC 2007; Roe and Baker 2007; Soden and Held 2006; Soden et al. 2008) which produces most of the uncertainty in the probability distributions shown in Fig. 1 (Roe and Baker 2007).

There are multiple methods that have attempted to determine $\mathrm{CS}$, all of which have different uncertainties (IPCC 2007). Use of glacial/interglacial paleo data has the advantage of long climate records, but also has concerns about observation accuracy, spatial sampling, and variations of CS from the peak of glacial epochs to the interglacial of today (Hansen et al. 2011; IPCC 2007). Ensemble distributions of climate model simulations (including perturbed physics ensembles) struggle to relate climate model prediction errors in climate base state or seasonal cycles to decade to century-scale CS uncertainties (IPCC 2007; Roe and Baker 2007; Murphy et al. 2004; Klocke et al. 2011). Efforts to relate climate change to $\mathrm{CO}_{2}$ concentrations over the last several decades struggle with both surface and air temperature accuracy (IPCC 2007; Karl et al. 2006; Hansen et al. 2010) and even more so with uncertainties in anthropogenic aerosol radiative forcing. Uncertainty in anthropogenic aerosol radiative forcing causes a factor of 3 uncertainty in the current total anthropogenic radiative forcing of the climate system (IPCC 2007; Hansen et al. 2005). Fortunately, recent advances in separating climate feedbacks in climate model simulations (Soden et al. 2008; Soden and Vecchi 2011) have helped clarify the observations needed on long time scales, including estimates of decadal changes in cloud radiative forcing for cloud feedbacks.

Obtaining a full set of observations of the feedbacks, along with the basic anthropogenic radiative forcing and global temperature response, would provide fully independent verification of CS. In the present paper, we do not consider all of these variables, but focus on global average temperature, which is key to observing climate system response. Measures of surface temperature and tropospheric air temperature are considered here. Future work can extend this to consider uncertainty in aerosol and cloud radiative forcing, but direct and indirect aerosol forcing are more complex issues than low cloud feedback (IPCC 2007; Hansen et al. 2005).

All estimates of anthropogenic climate change must be observed against the noise produced by natural variability of the climate system. This natural variability is driven primarily by the internal nonlinear dynamics of ocean and atmosphere in the climate system. Examples include ElNino Southern Oscillation (ENSO), Arctic Oscillation, and Pacific Oscillation, with ENSO typically providing the largest noise source for global means (Foster and Rahmstorf 2011; Lean and Rind 2009). Sources of external natural variability include solar variability and large volcanic eruptions such as Pinatubo (IPCC 2007; Lean and Rind 2009). In order to quantify uncertainty in decadal trends, we use the simplifying concept of linear decadal trends as a metric. While decadal change is not strictly linear, this assumption provides a very useful metric for understanding the effect of natural variability on uncertainty in observing anthropogenic trends (Weatherhead et al. 1998; Von Storch and Zwiers 1999; Leroy et al. 2008).

In addition to the noise of natural variability, climate trend uncertainty can also be increased by uncertainties in the COS. One of the largest sources of observing system uncertainty is changing calibration of satellite instruments over time (Leroy et al. 2008; Karl et al. 2006; Trenberth 
et al. 2012). This can be caused either by slow drifts of instrument calibration over years in orbit, or by differences in absolute calibration between successive instruments that either cannot be fully removed during overlap time periods, or cannot be removed because there is a time gap between the end of one observation and the start of its replacement. A second major source of observing system uncertainty is sampling error which can be caused either by limited space/time sampling or by systematic drifts in local time of day sampling for satellite instruments (Karl et al. 2006; IPCC 2007).

We can combine the sources of uncertainty in climate trends to determine the total uncertainty in a decadal trend ${ }^{3}$ $\delta m$ as (see Leroy et al. 2008, the Supplementary Online Material contains a derivation):

$(\delta m)^{2}=12(\Delta t)^{-3}\left(\sigma_{\mathrm{var}}^{2} \tau_{\mathrm{var}}+\sigma_{\mathrm{cal}}^{2} \tau_{\mathrm{cal}}+\sigma_{\text {orbit }}^{2} \tau_{\text {orbit }}\right)$

where $\Delta t$ is the length of observation period in years, $\sigma_{\mathrm{var}}^{2}$ is the variance of natural variability and $\tau_{\text {var }}$ is the autocorrelation time scale of natural variability. The observing system uncertainties include absolute calibration uncertainty $\sigma_{\text {cal }}^{2}$ and satellite orbit sampling uncertainty $\sigma_{\text {orbit }}^{2}$. Equation (1) is general enough to be used for any climate variable of interest such as temperature, water vapor, cloud height, sea level, or, for remote sensing observations, radiance, reflectance, or brightness temperature. In each case, the variable chosen determines the units of $\delta_{\mathrm{m}}, \sigma_{\mathrm{var}}^{2}$, $\sigma_{\text {cal }}^{2}$, and $\sigma_{\text {orbit }}^{2}$.

The time scales for satellite instrument calibration are taken as the instrument lifetime in order to allow for either instrument drift or gaps between instruments and is assumed to be 5 years, a typical design lifetime for an instrument in orbit (Leroy et al. 2008). The time units for $\Delta t$ and $\tau$ determine the time units for the trend $\delta_{m}$, and are taken as years for the values shown in Table 2 . The calculation in Eq. (1) uses absolute calibration uncertainty and not instrument stability as the more rigorous and robust uncertainty in future observations, since we cannot assume instruments will overlap, and often cannot prove whether or not they drift. This uncertainty is in essence the limit imposed by the need for more accurate traceability to physical standards (the Systeme International, or SI standards) in orbit. It is a conservative limit that is chosen in light of the high cost of societal decisions on climate change (Leroy et al. 2008; Wielicki et al. 2013). More complete discussions and derivations of Eq. (1) as well as the estimates of each error source can be found in Wielicki et al. (2013) and Leroy et al. (2008).

Figure 2 gives results for the $95 \%$ confidence bound (1.96 sigma for a two-sided Gaussian distribution) on

\footnotetext{
${ }^{3}$ The units in Eq. (1) are [C/year $]^{2}$, where $\mathrm{C}$ is degrees Celsius.
}

Table 2 Values of natural variability and observation uncertainties used in Eq. (2) for Fig. 2 (from Wielicki et al. 2013)

\begin{tabular}{|c|c|c|c|}
\hline \multirow[t]{3}{*}{ Uncertainty source } & \multicolumn{3}{|c|}{ Global temperature trend uncertainty } \\
\hline & \multicolumn{2}{|l|}{$\sigma(\mathrm{K})$} & \multirow{2}{*}{$\begin{array}{l}\tau \\
\text { Years }\end{array}$} \\
\hline & $\begin{array}{l}\text { CLARREO } \\
\text { improved COS }\end{array}$ & $\begin{array}{l}\text { I/A/C current } \\
\text { system }\end{array}$ & \\
\hline Natural variability & 0.085 & 0.085 & 2.3 \\
\hline Calibration uncertainty & 0.03 & 0.18 & 5 \\
\hline Orbit sampling uncertainty & 0.018 & 0.018 & 1 \\
\hline
\end{tabular}

climate trend accuracy for global average temperature. Table 2 provides the Eq. (1) values used in Fig. 2. The results are shown for a perfect observing system as well as varying levels of instrument absolute calibration. Temperature trend accuracy is a strong function of satellite calibration accuracy, but for accuracy below $0.06 \mathrm{~K}$ (95\% confidence), there is little further gain in improvements, and natural variability becomes the limiting factor for accuracy in climate trends. Current orbiting infrared spectrometers used to measure surface and atmospheric temperature vertical profiles (IASI, AIRS, CrIS, or I/A/C) have absolute radiometric accuracies ranging from 0.2 to $0.4 \mathrm{~K}$ (95\% confidence) (Hilton et al. 2012; EUMETSAT 2011). The CLARREO infrared spectrometer recommended by the NRC Decadal Survey (2007) would advance in-orbit calibration accuracy by roughly a factor of 5. Global temperature trends over the next few decades are expected to be $\sim 0.2 \mathrm{~K} /$ decade (IPCC 2007). Figure 2 shows, for example, that observing a warming trend of at least $0.1 \mathrm{~K} /$ decade with $95 \%$ confidence would require a 20-year observational record for a perfect observing system, 22 years for CLARREO, and more than 40 years for the IASI/AIRS/CrlS system. Alternatively, given 22 years of climate observation, a system with $0.36 \mathrm{~K}$ calibration accuracy could detect a trend of $0.3 \mathrm{~K} /$ decade or more with $95 \%$ confidence. ${ }^{4}$ A system with only $0.06 \mathrm{~K}$ calibration accuracy could detect trends of $0.1 \mathrm{~K} /$ decade or more.

Figure 2 suggests a framework for evaluating the economic impact of higher accuracy climate change observations by studying the ability to reach given levels of confidence earlier than for a less capable COS. While the examples given here are for one of the future CLARREO advances relative to current satellite sensors, the concept is general and can in principle be extended to a wide range of climate observations with economic impacts such as sea level rise, anthropogenic aerosol radiative forcing, carbon cycle, or ocean acidification. The next section provides an example of how to link the social cost of carbon discussed

\footnotetext{
$\overline{4}$ Specifically, a trend of $0.3 \mathrm{~K} /$ decade is outside the $[2.5 \%, 97.5 \%$ ] confidence band.
} 


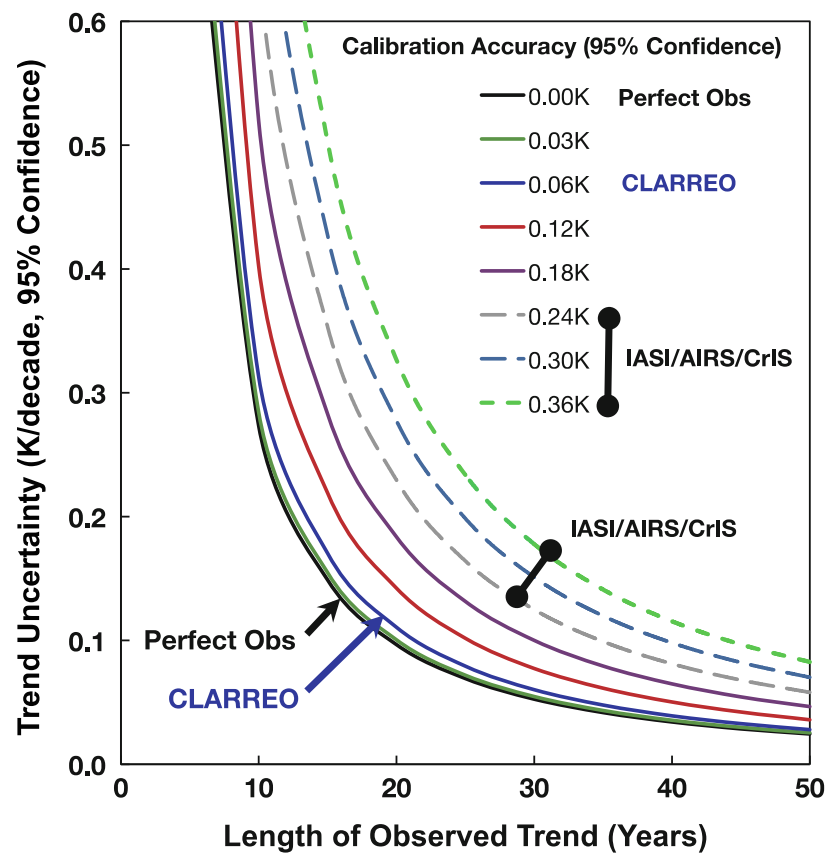

Fig. 2 The relationship between global average temperature trend accuracy, length of a climate record, and satellite sensor calibration absolute accuracy. Current satellite observations include IASI/AIRS/ CrIS weather sensors. CLARREO represents a future higher accuracy sensor following the NRC decadal survey recommendations (2007). From Wielicki et al. (2013)

in Sect. 2, with the climate observation trend accuracy in Sect. 3.

\section{Decision context for VOI calculations}

CLARREO is designed to learn the decadal rate of temperature rise faster than would be possible with existing global satellite observations. This knowledge is of no economic value, however, if it is not used. Using the USSCC baseline, we monetize this accelerated learning as averted damages by introducing a decision context in which this information is used to alter our emissions path. All calculations are performed with the IAM DICE, which is freely downloadable at http://nordhaus.econ.yale.edu/ DICE2007.htm. Four emissions paths define the decision context, BAU, the DICE Optimal path, a path stabilizing global temperature rise above the pre-industrial level ( $\lim 2.5 \mathrm{C}$ ), and a Stern report emissions path ${ }^{5}$ (see Table 3). Assuming an equilibrium $\mathrm{CS}$ of $3 \mathrm{C}$ for doubled $\mathrm{CO}_{2}$, Table 4 shows the damages and temperature rise associated

\footnotetext{
5 This is based on (Nordhaus 2008) where Stern industrial emissions per decade are given out to 2105 . Industrial emissions for Stern are zero beyond 2095. Total Stern emissions are determined by adding emissions due to land use changes, which are the same for all scenarios.
}

with these paths. Emissions and calculations of damages are extended out to 2205, though only the initial 2005-2115 are shown in Tables 3 and 4. Depending on discount rate, damages after 2115 have very little effect on NPV. At $2.5 \%$ discount rate, such damages are discounted over 100 years to $<8 \%$ of their 2115 value, while for a discount rate of $3 \%$ the damages are discounted to less than $5 \%$ of their 2115 value, and for a discount rate of $5 \%$ the damages are discounted to $<1 \%$ of their 2115 value.

The decision context used to calculate the VOI is as follows. It is assumed that we begin on the BAU path. A trigger variable $\Delta_{a}(C S, E(t))$, a trigger value $\Delta_{s}$, and a confidence level $Z_{s} \delta m$ are chosen. The trigger variable may be any observed climate variable, in this study, we focus on the decadal rate of global temperature rise. When the trigger value of the trigger variable is exceeded with the required confidence, we switch from the BAU path to an alternative path, which may be any of the other paths in Table 2. The trigger value is exceeded with the required confidence when

$\Delta_{a}(\mathrm{CS}, E(t))-10 Z_{s} \delta m>\Delta_{s}$

where $\Delta_{a}$ is the time varying anthropogenic climate trend of the climate variable of interest in the absence of natural variability. This trend is determined using the DICE IAM from Sect. 2 and is a function of equilibrium climate sensitivity CS and the time varying emissions scenario $E(t)$ as shown in Table 4 and Fig. 4. The units of this trend are the units of the climate variable being considered per decade (e.g., for temperature trends, ${ }^{\circ} \mathrm{C} /$ decade). The confidence level $Z_{s} \delta m$ is the one-sided $Z$ statistic for the desired societal decision confidence level (e.g. $Z_{s}=1.65$ for a onesided $95 \%$ confidence bound, and $Z_{s}=1.96$ for a onesided $97.5 \%$ confidence bound). The $Z$ statistic is unit-less and assumes a normal distribution for the current results. $\delta m$ is the standard deviation of uncertainty in anthropogenic change for the climate variable of interest. This uncertainty is determined in Eq. (1) and includes both natural variability and observing system uncertainty. For the results here, we use the values of Table 2 in Eq. (1). The factor of 10 in Eq. (2) converts the units of the climate variable of interest per year in Eq. (1) to per decade needed to be consistent with the other terms in Eq. (2). Finally, the societal decision trigger value $\Delta_{s}$ is the anthropogenic trend of the climate variable of interest that would spur society to take action and change emissions path through technology change and efficiency change. While CS is currently unknown to within a factor of $4, \Delta_{a}$ increases as CS increases (see Fig. 4 for temperature). Similar increases in trend absolute magnitude would typically be present for any climate variable considered (rainfall, cloud cover, hurricane intensity, etc.). As a result, when climate change trends become sufficiently large and sufficiently confident, 
Table 3 Total carbon emissions per year through 2115 for each of the 4 scenarios used in the VOI calculations

\begin{tabular}{lrrrrrrrrrrrr}
\hline \multicolumn{1}{l}{ Total carbon emissions (GTC per year) } \\
\cline { 2 - 11 } & 2005 & \multicolumn{1}{c}{2015} & \multicolumn{1}{c}{2025} & \multicolumn{1}{c}{2035} & \multicolumn{1}{c}{2045} & 2055 & 2065 & 2075 & 2085 & 2095 & 2105 & 2115 \\
\hline BAU & 9.058 & 10.463 & 12.395 & 14.566 & 16.741 & 18.716 & 20.388 & 21.699 & 22.593 & 23.158 & 23.361 & 22.640 \\
DICE Opt & 9.058 & 8.956 & 9.994 & 10.838 & 11.227 & 11.027 & 10.222 & 8.887 & 7.149 & 5.154 & 3.044 & 0.932 \\
Lim2.5C & 9.058 & 8.897 & 9.868 & 10.576 & 10.716 & 10.106 & 8.702 & 6.601 & 4.079 & 1.684 & 0.541 & 0.401 \\
Stern & 9.058 & 5.200 & 4.974 & 4.653 & 4.211 & 3.630 & 2.878 & 1.951 & 0.805 & 0.148 & 0.118 & 0.0945 \\
\hline
\end{tabular}

Table 4 Damages in trillion 2008 US international dollars per year and global surface air temperature warming above pre-industrial levels

\begin{tabular}{|c|c|c|c|c|c|c|c|c|c|c|c|c|}
\hline & \multicolumn{12}{|c|}{ For $\mathrm{CS}=3 \mathrm{C}$} \\
\hline & 2005 & 2015 & 2025 & 2035 & 2045 & 2055 & 2065 & 2075 & 2085 & 2095 & 2105 & 2115 \\
\hline BAU dam & 0.103 & 0.244 & 0.556 & 1.173 & 2.279 & 4.079 & 6.773 & 10.508 & 15.352 & 21.285 & 28.199 & 35.783 \\
\hline BAU temp & 0.731 & 0.947 & 1.198 & 1.477 & 1.781 & 2.102 & 2.433 & 2.766 & 3.093 & 3.410 & 3.711 & 3.986 \\
\hline DICE dam & 0.103 & 0.202 & 0.417 & 0.774 & 1.283 & 1.898 & 2.507 & 2.950 & 3.068 & 2.730 & 1.902 & 0.641 \\
\hline DICE temp & 0.731 & 0.938 & 1.164 & 1.401 & 1.642 & 1.879 & 2.101 & 2.300 & 2.468 & 2.600 & 2.692 & 2.735 \\
\hline $\lim 2.5$ dam & 0.103 & 0.200 & 0.410 & 0.750 & 1.209 & 1.702 & 2.058 & 2.066 & 1.592 & 0.752 & 0.238 & 0.197 \\
\hline $\lim \mathrm{d} .5$ temp & 0.731 & 0.938 & 1.162 & 1.397 & 1.633 & 1.861 & 2.068 & 2.243 & 2.376 & 2.461 & 2.500 & 2.500 \\
\hline Stern dam & 0.103 & 0.103 & 0.166 & 0.237 & 0.305 & 0.353 & 0.357 & 0.291 & 0.124 & 0.000 & 0.000 & 0.000 \\
\hline Stern temp & 0.731 & 0.916 & 1.081 & 1.226 & 1.353 & 1.461 & 1.549 & 1.616 & 1.658 & 1.676 & 1.676 & 1.661 \\
\hline
\end{tabular}

Damages and temperature warming are shown for each of the 4 scenarios used in the VOI calculations

society then reaches the trigger value and decides to move to a reduced emissions path. While societal decisions are complex and will typically involve trends in many climate variables, this initial study uses a simpler single variable to illustrate the general concept. Later studies can extend this concept to multiple climate variables as the decision trigger.

Using the decision trigger concept in Eq. (2), we compute the decision trigger time for the more accurate CLARREO advanced COS observation system as well as the current I/A/C satellite observations. We then compute the climate damages along the altered emissions paths. The difference between BAU damages and damages on the altered path are the averted damages. Upon choosing a discount rate, the NPV of averted damages is computed. The VOI of the CLARREO advanced COS is the surfeit of averted damage, relative to the existing I/A/C system. This VOI depends on when CLARREO is launched, the trigger value, the required confidence, and the reduced emissions path to which we switch. Note that the time to detection of the trigger value and the damages depend on the (uncertain) CS parameter. The decision context is summarized in Table 5.

Climate damages in DICE are computed in time period $i$ (we divide DICE's 10-year steps into two 5-year steps) by decrementing global output in period $i$ by the factor $1 /\left[1+0.00284 \times \Delta T^{2}(i)\right]$, where $\Delta T(i)$ is the atmospheric temperature in period $i$ in degrees Celsius above pre-
Table 5 Decision context

\begin{tabular}{llll}
\hline Trigger variable & \multicolumn{2}{l}{ Global temperature change/decade } & \\
\hline Trigger value $\Delta_{s}$ & Freely choose & & \\
Confidence level $Z_{s}$ & Freely choose & & \\
\hline Launch date & After 2020 in 5-year steps & Stern \\
\cline { 2 - 4 } $\begin{array}{l}\text { Altered emissions } \\
\text { policy: switch from }\end{array}$ & DICE Opt & Lim 2.5C & \\
$\begin{array}{l}\text { BAU to: } \\
\text { Discount rate }\end{array}$ & $2.50 \%$ & $3 \%$ & $5 \%$ \\
\hline
\end{tabular}

industrial average. $\Delta T(i)$ is computed in DICE using total emissions up to time period $i$. The relationship between industrial output and emissions in the BAU scenario is also used for the reduced emissions scenarios. This means that emissions reductions are not modeled as intelligently phasing out the dirtiest technologies first. Flanking studies confirmed that the difference in averted damages between CLARREO and the current system are insensitive to the method of emissions reductions. Note that choosing the trigger value and/or the confidence very high would make it unlikely that the trigger would be pulled with either the new or current COS. Similarly, choosing the trigger value and/or the confidence level very low would cause the trigger to be pulled immediately for both systems. In either case, the VOI of CLARREO above the current system 


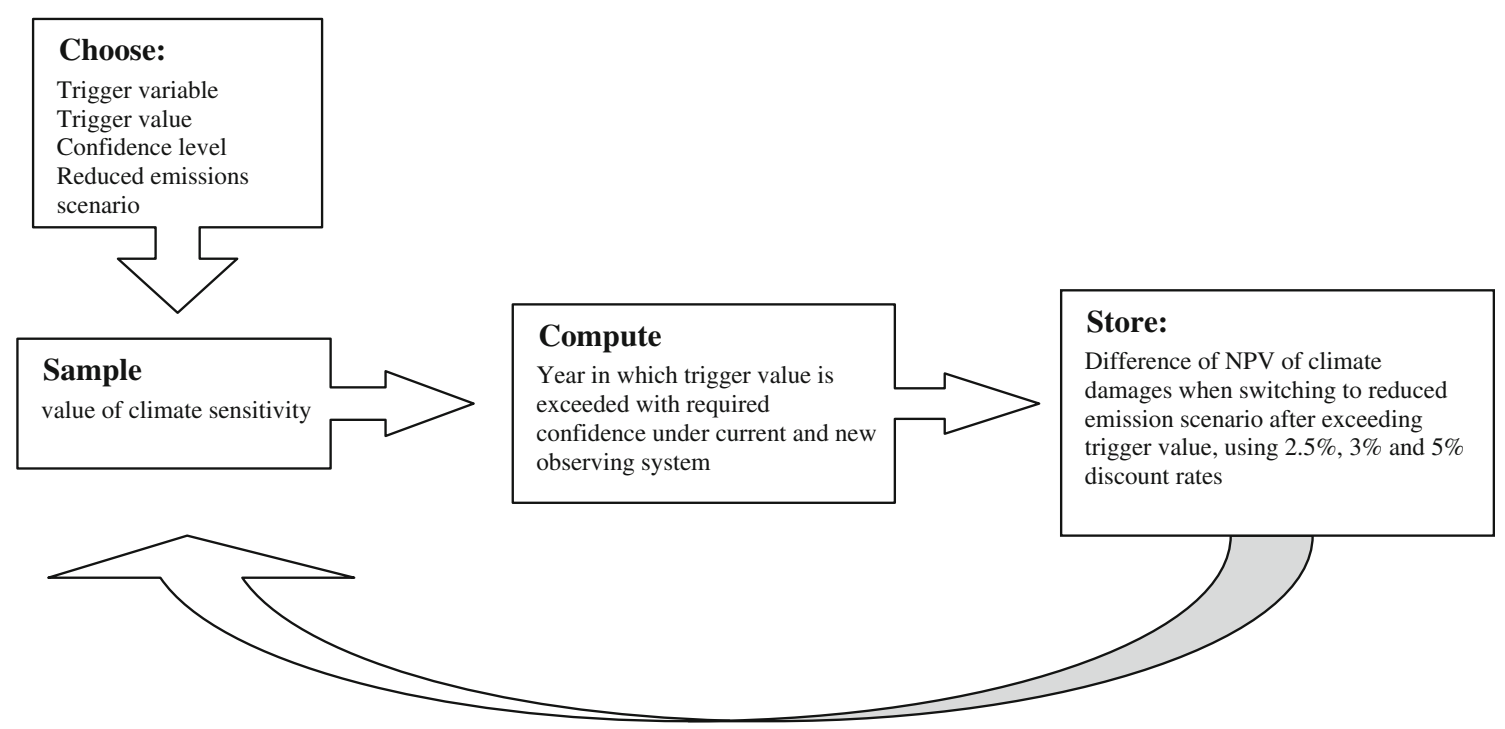

Fig. 3 Calculation flow chart. The loop for sampling of climate sensitivity values is carried out over the frequency distribution shown in Fig. 1

would be zero. The trigger value and confidence level should reflect society's risk tolerance. High values are very risk tolerant, low values are very risk intolerant. A flow chart for the calculations is given in Fig. 3.

Predicting global mean temperature on a 100 -year time scale depends on the CS and on the emissions scenario. The value of greater accuracy on decadal time scales is related to the fact that different values of CS are difficult to distinguish in early decades. Figure 4 shows the temperature rise above pre-industrial levels as a function of time for values of CS spanning the possible range, assuming the BAU emissions scenario. A gain in accuracy for temperature rise on decadal scales would leverage large gains in accuracy on century scales, especially for high CS scenarios.

\section{Results}

The difference in averted damages based on the CLARREO and on the existing I/A/C observing system depends on the year at which the trigger value is exceeded with required confidence with these two systems. Consulting Eq. (2), it is clear that reducing the magnitude of the positive definite $\delta m$ (left hand side of Eq. 1) leads to reaching this confidence earlier, though when that happens depends on the unknown CS. Figure 5 shows plots of the time at which the trigger value is exceeded with the required confidence for three observing systems. A perfect observing system has to contend only with natural variability, but not with calibration or sampling uncertainty. "Perf" shows the time at which a perfect observing system would yield the required certainty that the trigger value had been exceeded. CLARREO ("CLAR") and the current system ("I/A/C") have to contend with natural variability and with these latter two sources of uncertainty, as described in Eq. (1) and Table 2. Figure 4 compares 4 different settings of decision parameters. The first (upper left panel) is the base case: CLARREO is launched in 2020, and we require $95 \%$ confidence that the trigger value of $0.2 \mathrm{C} / \mathrm{dec}$ ade is exceeded. In this case, we see that, if CS is 4 , then the perfect observing system discovers this fact with $95 \%$ certainty in 2035, CLARREO makes the same discovery in 2040, whereas I/A/C does not become $95 \%$ certain until 2050.

Raising the trigger value to $0.3 \mathrm{C}$ (upper right panel) shifts all curves up and to the right, and makes the difference between CLAR and I/A/C a little larger. Requiring higher confidence $(97.5 \%)$ increases the separation between CLARREO and I/A/C (lower right panel). Delaying the launch to 2030 (lower left panel) decreases the difference between CLAR and I/A/C, as the latter system has a longer head start. We start both observing systems in 2020 for the base case because of the current large uncertainties in total anthropogenic forcing of the climate system. But these uncertainties will reduce as

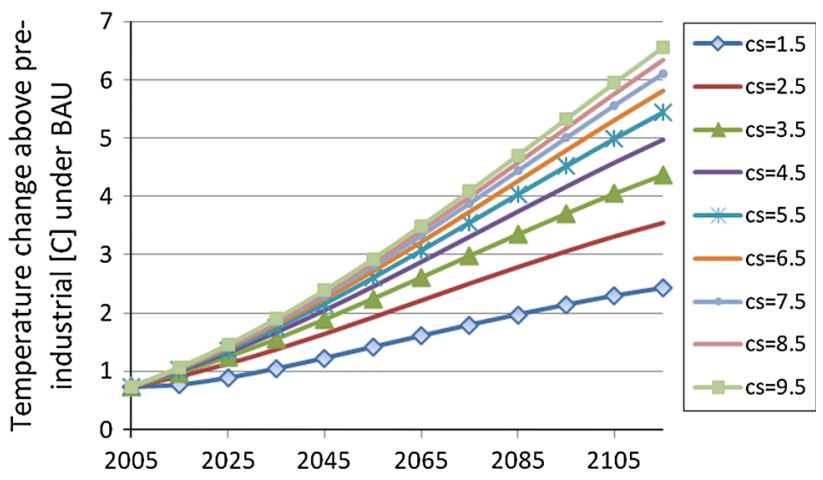

Fig. 4 Temperature rise for different climate sensitivities under BAU 
decadal temperature rise

launch 2020 conf $95 \%$ trigger $0.2 \mathrm{C}$

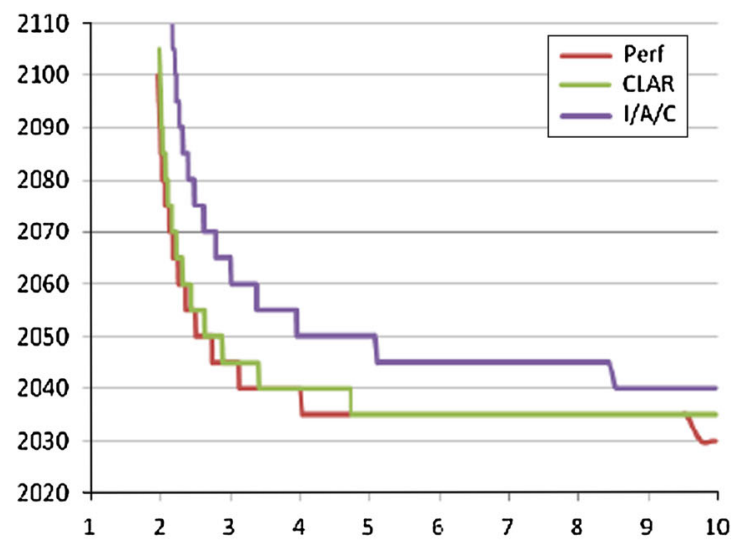

decadal temperature rise

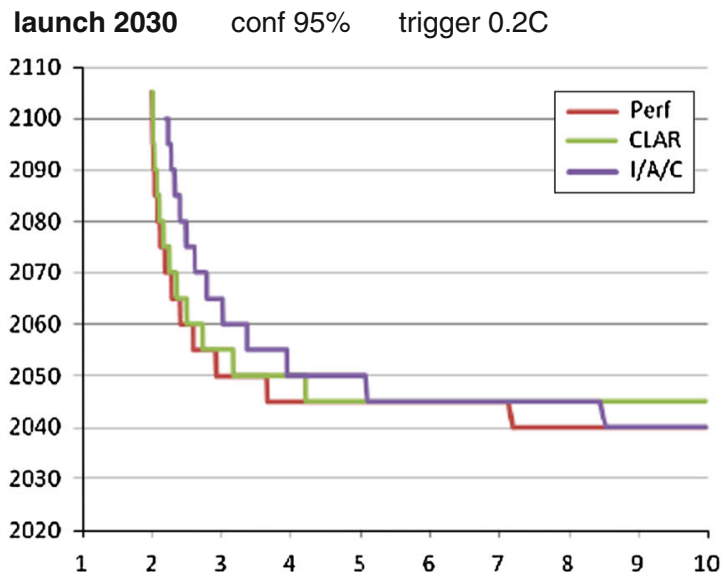

launch $2020 \quad$ conf $95 \% \quad$ trigger $\mathbf{0 . 3 C}$

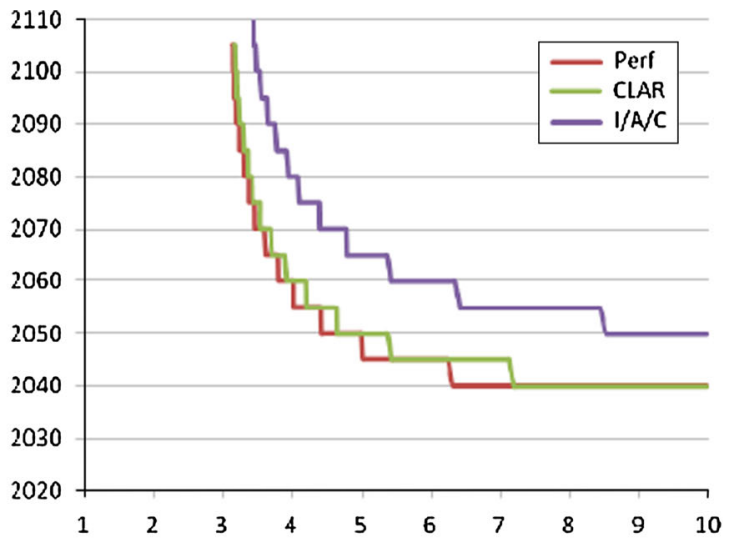

launch 2020 conf $\mathbf{9 7 . 5 \%}$ trigger $0.2 \mathrm{C}$

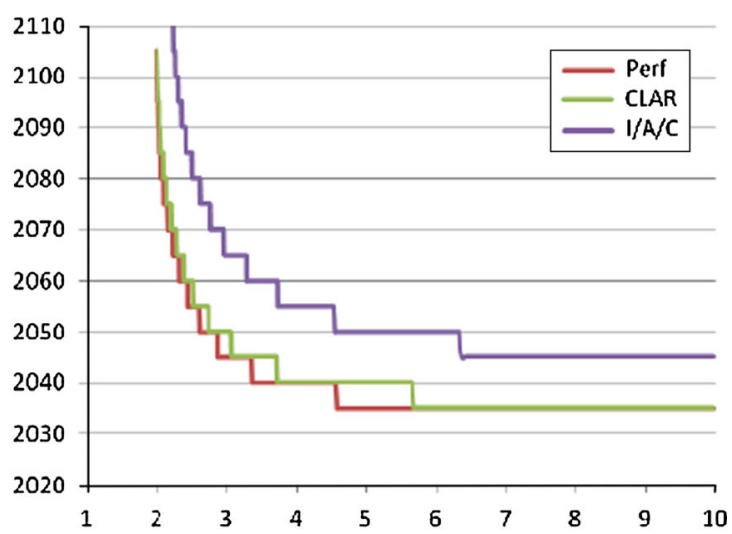

Fig. 5 Year in which trigger value of decadal temperature rise is exceeded with given confidence, as function of climate sensitivity

aerosol forcing climate science improves and as greenhouse gas emissions increase their fraction of total climate forcing with time (IPCC 2007).

In the base case (upper left panel of Fig. 5), when the switch from the BAU to a reduced emissions scenario is triggered by $95 \%$ certainty of at least $0.2{ }^{\circ} \mathrm{C}$ temperature rise per decade, then the averted damages, given $\mathrm{CS}=4$, will be lower between 2040 and 2050 if we have the CLARREO system. To compute the VOI of CLARREO in this base case, we compute the NPV (under various discount rates) for each value of $\mathrm{CS}$ of the difference in averted damages with and without CLARREO and take their expected value over the frequency distribution in Fig. 1.

Table 6 shows the NPV of the difference in averted damages when switching from BAU to DICE Optimal emissions is triggered by $95 \%$ confidence that decadal temperature rise exceeds $0.2{ }^{\circ} \mathrm{C}$, with a 2020 launch date. When discounting at $2.5 \%$, damages in the future are valued more highly and the difference in averted damages is 17.55 trillion USD (2008); using a $5 \%$ discount rate reduces the importance and the NPV of the difference in averted damages becomes 3.14 trillion USD (2008), while the nominal $3 \%$ discount rate gives averted damages of 11.67 trillion. It must be emphasized that these are worldwide damages. Using IMF projections out to $2050^{6}$ and extrapolating out to 2115 , VOI in averted US damages is 7.2, 3.8, and 0.54 trillion USD for discount rates of 2.5, 3 , and $5 \%$, respectively.

This analysis makes several simplifying assumptions. Sensitivity of results to these assumptions can be partially addressed by running the calculations under variations of parameter settings for the decision context. Table 7 shows the base case and 7 variations. "Delta mean averted damages" denotes the mean NPV of averted damages under the

\footnotetext{
${ }^{6} \mathrm{http} / / /$ en.wikipedia.org/wiki/List_of_countries_by_past_and_future GDP_(nominal).
} 
Table 6 VOI for CLARREO in base case

\begin{tabular}{|c|c|c|c|c|c|}
\hline & \multicolumn{5}{|c|}{ VOI: BAU $\rightarrow$ DICE optimum emissions; Launch $=2020$, Conf $=95 \%$, Trigger $=0.2{ }^{\circ} \mathrm{C}$} \\
\hline & $\begin{array}{l}\text { BAU and altered } \\
\text { emissions path }\end{array}$ & $\begin{array}{l}\text { Mean NPV damages } \\
\text { trillion USD } 2008\end{array}$ & SD & $\begin{array}{l}\text { Delta mean averted damages: } \\
\text { increase in VOI with CLARREO } \\
\text { advanced COS over I/A/C } \\
\text { current observations }\end{array}$ & \\
\hline & BAU $2.5 \%$ & 345.39 & 158.66 & $2.5 \%$ & 17.55 \\
\hline & BAU $3 \%$ & 209.14 & 92.58 & $3 \%$ & 11.67 \\
\hline & BAU $5 \%$ & 43.02 & 16.13 & $5 \%$ & 3.14 \\
\hline \multirow[t]{3}{*}{ Discovered by CLARREO } & VOI-CLARREO $2.5 \%$ & 73.10 & 35.95 & & \\
\hline & VOI-CLARREO $3 \%$ & 53.58 & 20.01 & & \\
\hline & VOI-CLARREO $5 \%$ & 20.12 & 3.38 & & \\
\hline \multirow[t]{3}{*}{ Discovered by A/C/I } & VOI-I/A/C $2.5 \%$ & 90.65 & 41.05 & & \\
\hline & VOI-I/A/C $3 \%$ & 65.24 & 21.69 & & \\
\hline & VOI-I/A/C $5 \%$ & 23.26 & 2.87 & & \\
\hline
\end{tabular}

Table 7 CLARREO VOI results for decadal temperature rise

\begin{tabular}{|c|c|c|c|c|c|c|c|}
\hline \multirow{2}{*}{$\begin{array}{l}\text { Table } 7 \text { CLARREO VOI } \\
\text { results for decadal temperature } \\
\text { rise }\end{array}$} & \multicolumn{7}{|c|}{ Delta mean averted damages trillion USD (2008) } \\
\hline & Launch date & Switch to & Confidence $(\%)$ & Trigger (C/decade) & $2.5 \%$ & $3 \%$ & $5 \%$ \\
\hline & 2020 & DICE OPT & 95 & 0.2 & 17.55 & 11.67 & 3.14 \\
\hline & 2020 & DICE OPT & 97.5 & 0.2 & 21.63 & 14.22 & 3.66 \\
\hline & 2030 & DICE OPT & 95 & 0.2 & 14.79 & 9.16 & 1.88 \\
\hline & 2020 & DICE OPT & 95 & 0.3 & 23.34 & 14.36 & 2.91 \\
\hline & 2020 & STERN & 95 & 0.2 & 22.25 & 15.57 & 5.01 \\
\hline & 2020 & STERN & 97.5 & 0.2 & 27.19 & 18.78 & 5.75 \\
\hline & 2020 & STERN & 97.5 & 0.3 & 31.86 & 20.30 & 4.65 \\
\hline Values in bold are departures & 2030 & STERN & 97.5 & 0.3 & 30.61 & 18.54 & 3.50 \\
\hline
\end{tabular}

Values in bold are departures

from base case

existing I/A/C system minus the mean NPV of averted damages under CLARREO. This is the VOI of CLARREO in the stipulated decision context.

Raising the trigger value or the required confidence increases the difference in time between discovery of exceedence with CLARREO and the existing system. Hence, the NPV of mean averted damages increases relative to the base case. Switching to a more aggressive emissions reduction scenario also increases the difference in damages between the two observing systems. On the other hand, delaying the launch time gives the existing system a greater head start and reduces the mean averted damages of CLARREO. Comparing the 2020 CLARREO launch VOI with the 2030 launch VOI allows an estimate of the cost of delaying an advanced COS at roughly 250 billion USD in NPV per year of delay. Given the fact that the STERN emissions scenario is much more aggressive than the DICE optimal scenario, one might have expected that switching from BAU to STERN instead of DICE OPT would have a greater impact on CLARREO's VOI. The results are explained by noting that mean averted damages are the differences in the NPV of damages when the switch is triggered by the two observing systems.

\section{Conclusion}

In all cases shown in Table 7, the VOI of an advanced COS using the CLARREO example appears to be large relative to their cost. Current climate observations costs in the US are roughly 2.5 billion USD/year (USGCRP 2012), with international efforts of roughly similar magnitude for a total of 5 billion USD/year on climate observations. A complete advanced COS might easily reach 3 times these costs, or roughly an additional 10 billion USD/year globally. These additional costs would include advances in climate monitoring, climate process studies, as well as advanced climate modeling. Such an advanced COS might then cost 200-250 billion USD in total NPV for 30 years of observations from 2020 to 2050 . But relative to the VOI estimates in this paper at 2-30 trillion USD in NPV, such an investment would pay back between 8 and 120 USD per dollar invested. 
While CLARREO is used as the example to demonstrate the concept, societal decisions will be made using many climate change signals, so that this value should be considered to be relevant to an improved overall COS. A number of caveats apply to these calculations:

1. Following the SCC, only damages are considered in computing the social cost of carbon. Switching to a reduced emissions scenario undoubtedly entails costs which themselves depend on many uncertain parameters on both the climate and the economic side. It is important to appreciate that the SCC is not solving a social choice problem, it is computing a price that should be added to the price of carbon to account for environmental damages. As analogy, the amount we should be willing to pay for a low emissions car depends on the damages averted by reduced emissions. In the same way, the amount we should be willing to pay for an improved COS depends on the value of averted damages. This is what the VOI computes. Mitigation costs are not included in the analysis as they have no traceability equivalent to that for damages in the SCC. For example, mitigation cost estimates in the IPCC report (2007) vary by a factor of 12 for achieving stabilization of $\mathrm{CO}_{2}$ at $535-590 \mathrm{ppm}$. Future VOI developments should examine inclusion of these costs.

2. Again following the SCC, only CS is considered uncertain. There are many other uncertain parameters in these calculations, including the carbon cycle, ice sheet dynamics, economic damages, and abatement costs. Agreement on uncertainty distributions for these other uncertain parameters would enable improvements in the present calculations.

3. Observing the decadal temperature rise is not the only way to learn about CS, nor is it the best way. Observing cloud radiative forcing and temperature change together provide more direct information about cloud feedbacks and therefore CS (Dessler 2010; Soden et al. 2008). While not shown here, a similar advance in the knowledge of cloud radiative forcing and cloud feedback using CLARREO higher accuracy reflected solar radiation observations has been shown in Wielicki et al. (2013).

4. Any real decision context is more complex than that modeled here. For example, these calculations assume that a switch to a reduced emissions scenario would happen instantaneously, on a time scale discretized into 5-year steps. A policy ramp would be more realistic, involving additional decision parameters. Since this policy ramp would apply to switches under both the new and current observing systems, its effect might be relatively small on VOI values.
Despite these caveats, the results show that a uniform yardstick, however imperfect, can enable calculations supporting complex social decisions. The same method could be used with improved climate and economic models and with a broader range of uncertain inputs. This in itself will hopefully motivate improvements in second generation tools for computing the social cost of carbon, as well as a better understanding of the economic value of future advances in climate observations.

Open Access This article is distributed under the terms of the Creative Commons Attribution License which permits any use, distribution, and reproduction in any medium, provided the original author(s) and the source are credited.

\section{References}

Anthoff D, Tol RSJ (2010) The climate framework for uncertainty, negotiation and distribution (FUND). Technical description, version 3.5. URL:http://www.fund-model.org/

Arrow KJ, Cline WR, Maler K-G, Munasinghe M, Squitieri R, Stiglitz JE (1996) Intertemporal equity, discounting, and economic efficiency, In: Climate change 1995: economic and social dimensions of climate change, contribution of working group III to the second assessment report of the IPCC

Brathwaite J, Saleh JH (2013) Bayesian framework for assessing the value of scientific space systems: value of information approach with application to earth science spacecraft. Acta Astronaut 84:24-35

CCSP (2003) Strategic plan for the U.S. Climate Change Science Program, U.S. Climate Change Science Program. www. climatescience.gov, p 202

Cooke RM (2012) Uncertainty analysis comes to integrated assessment models for climate change... and conversely. Clim Change 117(3):467-479. doi:10.1007/s10584-012-0634-y

Dessler AE (2010) Clouds and the earth's energy budget, geophys. Res Lett 38:L19701. doi:10.1029/2011GL049236

EUMETSAT 2011: GSICS traceability statement for IASI and AIRS, Doc. No. EUM/MET/TEN/11/0157, DCN No. 3786830, 16 March 2011

Foster G, Rahmstorf S (2011) Global temperature evolution 1979-2010. Environ Res Lett 6:8. doi:10.1088/1748-9326/6/4/044022

Freebairn JW, Zillman JW (2002) Economic benefits of meteorological services. Meteorol Appl 9:33-44

Global Climate Observing System (GCOS) (2011) Systematic observation requirements for satellite-based data products for climate, 2011 update. GCOS-154, WMO, p 128

Group on Earth Observations (GEO) (2005) The global earth observation system of systems (GEOSS) 10-year implementation plan. http://www.earthobservations.org/documents/10-year\%20 Implementation\%20Plan

Group on Earth Observations (GEO) (2010) A quality assurance framework for earth observation: principles, version 4. Jan 2010. http://qa4eo.org/docs/QA4EO_Principles_v4.0.pdf

Hansen J et al (2005) Efficacy of climate forcings. J Geophys Res 110:D18104. doi:10.1029/2005JD005776

Hansen J, Ruedy R, Sato M, Lo K (2010) Global surface temperature change. Rev Geophys 48:RG4004. doi:10.1029/2010RG000345

Hansen J, Sato M, Kharecha P, von Schuckmann K (2011) Earth's energy imbalance and implications. Atmos Chem Phys 11: 27031-27105 
Hilton F et al (2012) Hyperspectral earth observations from IASI: five years of accomplishments. Bull Am Meteorol Soc 93:347-370

Hope C (2006) The marginal impact of CO2 from PAGE2002: An integrated assessment modelincorporating the IPCC's five reasons for concern. Integr Assess 6:19-56

Hurrell J, Meehl GA, Bader D, Delworth T, Kirtman B, Wielicki B (2009) A unified modeling approach to climate system prediction. Bull Am Meteorol Soc 90:1819-1832

IPCC (Intergovernmental Panel on Climate Change) (2007) Climate change 2007: the physical science basis, working group I contribution to the fourth assessment report of the IPCC. Cambridge University Press, New York

IWG SCC (Interagency Working Group on Social Cost of Carbon, U.S. government) (2010). Social cost of carbon for regulatory impact analysis under executive order 12866, Appendix 15a, Washington DC. http://www.epa.gov/otaq/climate/regulations/ scc-tsd.pdf

Karl TR, Hassol SJ, Miller CD, Murray WL (2006) Synthesis and assessment product 1.1 report by the U.S. Climate Change Science Program and the Subcommittee on Global Change Research. U.S. Climate Change Science Program, April, 2006, p 164

Katz RW, Murphy AH (eds) (2005) "Economic value of weather and climate forecasts”, IBSN: 9780521435710 , Cambridge University Press

Kelly DL, Kolstad CD (1999) Bayesian learning, growth, and pollution. J Econ Dyn Control 23(4):491-518

Klocke D, Pincus R, Quaas J (2011) On constraining estimates of climate sensitivity with present day observations through model weighting. J Clim 24:6092-6099

Kopp RE, Mignone BK (2012) The U.S. government's social cost of carbon estimates after their first two years: Pathways for improvement. Econ 6:2012-2015

Laxminarayan R, Macauley MK (eds) (2012) The value of information methodological frontiers and new applications in environment and health. Springer, Dordrecht. doi:10.1007/978-94-0074839-2

Lean JL, Rind DH (2009) How will Earth's surface temperature change in future decades? Geophys Res Lett 36:L15708. doi:10. 1029/2009GL038932

Leroy SS, Anderson JG, Ohring G (2008) Climate signal detection times and constraints on climate benchmark accuracy requirements. J Clim 21:184-846

McInerney D, Lempert R, and Keller K (2011) What are robust strategies in the face of uncertain climate threshold responses? Clim Change. doi:10.1007/s10584-011-0377-1

Morss RE, Lazo JK, Brown BG, Brooks HE, Ganderton PT, Mills BN (2008) Societal and economic research and applications for weather forecasts. Bull Am Meteorol Soc 89:335-346

Murphy JM, Sexton DMH, Barnett DN, Jones GS, Webb MJ, Collins M, Stainforth DA (2004) Quantification of modelling uncertainties in a large ensemble of climate change simulations. Nature. doi:10.1038/nature02771
Nordhaus WD (2008) A question of balance: weighing the options on global warming policies. Yale University Press, New Haven

NRC (2007) Earth science and applications from space: national imperatives for the next decade and beyond. National Academy Press, Washington D.C.

Ohring G (ed) (2007) Achieving satellite instrument calibration for climate change $\left(\mathrm{ASIC}^{3}\right)$. NOAA, Washington D.C.

Ohring GB, Wielicki BA, Spencer R, Emery B, Datla R (2005) Satellite instrument calibration for measuring global climate change: report on a workshop. Bull Am Meteorol Soc 86: $1303-1313$

O’Neill B, Crutzen CP, Gruebler A, Duong MH, Keller K, Kolstad C, Koomey J, Lange A, Obersteiner M, Oppenheimer M, Pepper W, Sanderson W, Schlesinger M, Treich N, Ulph A, Webster M, Wilson C (2006) Learning and climate change. Clim Policy 6:585-589

Roe GH, Baker MB (2007) Why is climate sensitivity so unpredictable? Science 318(5850):629-632

Soden BJ, Held IM (2006) An assessment of climate feedbacks in coupled ocean-atmosphere model. J Clim 19:3354-3360

Soden BJ, Vecchi GA (2011) The vertical distribution of cloud feedback in coupled ocean-atmosphere models. Geophys Res Lett 38:L12704. doi:10.1029/2011GL047632

Soden BJ, Held IM, Colman R, Shell KM, Kiehl JT, Shields CA (2008) Quantifying climate feedbacks using radiative kernels. J Clim 21:3504-3520

Stern N (2008) The economics of climate change. Am Econ Rev 98(2):1-37

Teisberg TJ, Weiher RF, Khotanzad A (2005) The economic value of temperature forecasts in electricity generation. Bull Am Meteorol Soc 86:1765-1771

Tol RS (2002) Estimates of the damage costs of climate change. Part 1: benchmark estimates. Environ Resour Econ 21(1):47-73

Tol RS (2005) The marginal costs of carbon dioxide emissions: an assessment of the uncertainties. Energy Policy 33(16):2064-2074

Trenberth KE, Belward A, Brown O, Haberman E, Karl TR, Running S, Ryan B, Tanner M, Wielicki BA (2012) Challenges of a sustained climate observing system, in the monograph. In: Asrar GR, Hurrell JW (eds) Climate science for serving society: research, modelling and prediction priorities. Springer, New York

USGCRP (2012) Our changing planet. http://library.globalchange. gov/our-changing-planet-2013

Von Storch H, Zwiers FW (1999) Statistical analysis in climate research. Cambridge University Press, New York

Weatherhead EC et al (1998) Factors affecting the detection of trends: statistical considerations and applications to environmental data. J Geophys Res 103:17149-17161

Webster M, Jakobovits L, Norton J (2008) Learning about climate change and implications for near-term policy. Clim Change 89:67-85. doi:10.1007/s10584-008-9406-0

Wielicki BA et al (2013) Achieving climate change absolute accuracy in orbit. Bull Am Meteorol Soc (in press) 